\title{
Study on Flow Field Performances of Oil Film Bearing in High-Speed Roll Grinder Based On FLUENT
}

\author{
H.C. Wu, S.T. Chen, X.J. Meng, K.J. Linghu \\ School of Mechanical Engineering \\ Guizhou University \\ Guiyang, China
}

\begin{abstract}
Flow field performances of a kind of oil film bearing in high-speed roll grinder are revealed by means of FLUENT fluid dynamics software, and structure defects of the bearing are found. On these bases, structure of the bearing is improved, and flow field performances of the bearing are analyzed again, and the analysis results show as follows: diffusibility of oil film pressure for the improved bearing is enhanced, the phenomenon of oil outflow is restrained effectively, and the whole oil flow is accelerated, thus, heat dissipation property and pocketed oil phenomenon of the bearing are improved effectively. Therefore, flow field performances of the improved bearing are good, which lays the theoretical foundation for its practical application.
\end{abstract}

Keywords-roll grinder; high-speed grinding; oil film bearing; flow field

\section{INTRODUCTION}

Grinding is a kind of machining method of depending on plenty of wear particles on the surface of grinding wheel as cutting edge to remove material. Generally, Grinding can be divided into three categories according to the linear velocity (V) of grinding wheel: common grinding ( $\mathrm{V}<45 \mathrm{~m} / \mathrm{s})$, highspeed grinding $(45 \leqslant \mathrm{~V}<150 \mathrm{~m} / \mathrm{s})$, ultrahigh speed grinding $(\mathrm{V} \geqslant 150 \mathrm{~m} / \mathrm{s})$ [1]. Since $1990 \mathrm{~s}$, benefits brought by highspeed and ultrahigh speed grinding have been gradually recognized, thus, high-speed and ultrahigh speed grinding technologies have been paid more and more attentions, and on the bases of experiments and researches, these technologies have obtained rapid development [2]. Development of high-speed and ultrahigh speed grinding technologies is very rapid in some developed countries such as Germany, Japan and America, and in comparison with these developed countries, development in our country is relative slow [3-5].

Bearing technology of the spindle in high-speed and ultrahigh speed grinder is a key technology for high-speed and ultrahigh speed grinding [6]. At present, liquid hybrid oil film bearing has been widely used in high-speed and ultrahigh speed roll grinder. In the course of high-speed running of high-speed grinder, complete oil film should be kept for liquid hybrid oil film bearing, so, in order to maintain pure liquid friction between the liquid hybrid oil film bearing and the spindle of high-speed grinder and avoid scratch and other lubrication failure phenomena induced by metal contact, flow field performances of the bearing must be studied in detail, so that analysis basis can be provided for revealing formation mechanism of the oil film. On the other hand, most of heat generated by friction pair between the spindle and the bearing in the course of high-speed running needs to be carried away by the flow of lubrication oil. Therefore, study on flow field performances of the highspeed oil film bearing has not only important significant for studying its lubrication theory, but also has important function for analyzing its thermal effect [7].

Reynolds equation lays a foundation for solving fluid lubrication problem, but its derivation process involves in many simplifications and hypotheses, such as neglecting the inertial items, supposing invariable viscosity and density, and so on [8]. As universal fluid analysis software, FLUENT is now widely applied in Computational Fluid Dynamics (CFD) analysis of complicated flow field. In comparison with traditional method of solving Reynolds equation, FLUENT software has advantages in analyzing complicated turbulent current model.

In this paper, aiming at a kind of liquid hybrid oil film bearing in high-speed roll grinder, its flow field performances before and after improvement will be revealed by means of FLUENT fluid dynamics software, so that theory support for its practical application can be provided.

IISTRUCTURE OF THE OIL FILM BEARING IN HiGH-SPEED ROLL GRINDER AND OIL FILM MODEL

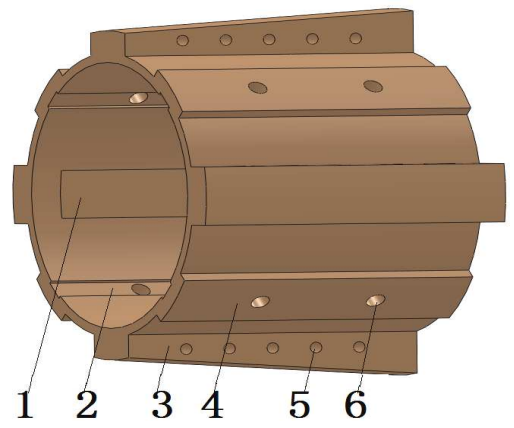

1. Static pressure oil cavity; 2. Oil guide groove; 3 . Tapered rib;4. Rectangle rib; 5. Oil guide hole; 6 . Oil entrance hole

FIGURE I. STRUCTURE OF THE BEARING BODY OF THE OIL FILM BEARING IN HIGH-SPEED ROLL GRINDER. 
Structure of the bearing body of the oil film bearing in high-speed roll grinder is shown in Figure.1, and the bearing body is matched with a bearing sleeve. Under the action of interference fit between each tapered rib on the bearing body and the bearing sleeve, sunken deformation occurs on the bearing, thus, eight wedge-type dynamic pressure oil cavities are forced to form, which guarantees the structure condition for forming dynamic pressure in the course of running of the bearing. In order to prevent dry friction in the course of starting and stopping, four static pressure oil cavities are designed on the inner surface of the bearing; in order to enhance the intensity of the bearing body, rectangle rib is designed in the middle of each two tapered ribs, and two oil entrance holes are designed on each rectangle rib; in order to reinforce the effect of oil diffusion, four oil guide grooves are designed in inner surface of the bearing.

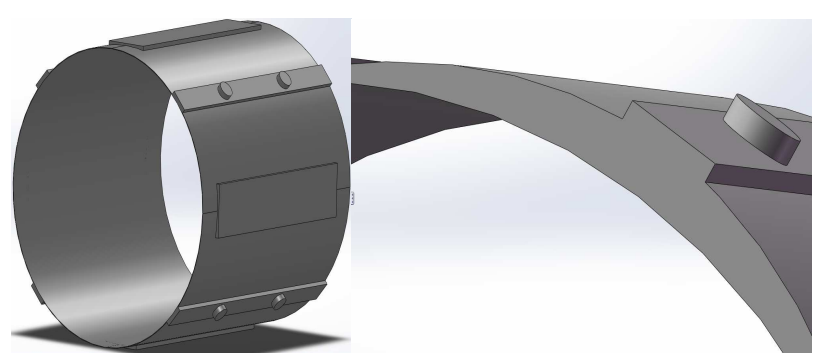

$\begin{array}{ll}\text { (a) Oil film structure } & \text { (b) Enlarged view of lateral edge }\end{array}$

FIGURE II. OIL FILM MODEL OF THE OIL FILM BEARING IN HIGH-SPEED ROLL GRINDER.

TABLE I. MAIN PARAMETERS OF THE OIL FILM MODEL.

\begin{tabular}{|c|c|}
\hline Parameters & Dimension (mm) \\
\hline Length & 100 \\
\hline Width & 100 \\
\hline Minimum thickness & 0.2 \\
\hline Radius of the oil entrance hole & 3 \\
\hline Depth of the static pressure oil cavity & 1.5 \\
\hline Length of the static pressure oil cavity & 80 \\
\hline Width of the static pressure oil cavity & 12 \\
\hline Depth of the oil guide groove & 1.5 \\
\hline Length of the oil guide groove & 100 \\
\hline Width of the oil guide groove & 8 \\
\hline
\end{tabular}

In order to analyze flow field performances of the oil film bearing, its oil film model needs to be built. Based on the structure of the bearing shown in Figure.1, oil film structure of the bearing is built, as is shown in Figure.2 (a). Because lateral edge of the oil film structure is a wedge-type structure, its enlarged view is given especially, as is shown in Figure.2 (b). Some main parameters of the oil film model are shown in Table 1.
III Simulation CALCUlation OF Flow Field OF THE OIL FILM BEARING IN HIGH-SPEED ROLL GRINDER

The bearing shown in Figure. 1 is applied in high-speed roll grinder whose spindle speed is $1500 \mathrm{r} / \mathrm{min}$. On this basis, flow field of the bearing is calculated by means of FLUENT fluid dynamics software to reveal pressure distribution and oil flow performances in high-speed running condition. Some main parameters for the calculation are as follows: oil pressure is $5 \mathrm{MPa}$, dynamic viscosity of lubrication oil is $0.01668 \mathrm{~Pa} \cdot \mathrm{s}$, density is $874 \mathrm{~kg} / \mathrm{m} 3$, specific heat is $1886 \mathrm{~J} /(\mathrm{kg} \cdot \mathrm{K})$, and thermal conductivity is $0.14 \mathrm{w} /(\mathrm{m} \cdot \mathrm{K})$.

Figure. 3 and Figure. 4 show the calculation results at the spindle speed of $1500 \mathrm{r} / \mathrm{min}$, in which, Figure. 3 shows the pressure distribution and gradient graphs of the oil film bearing, and Figure. 4 shows oil flow distribution graph of the oil film bearing.

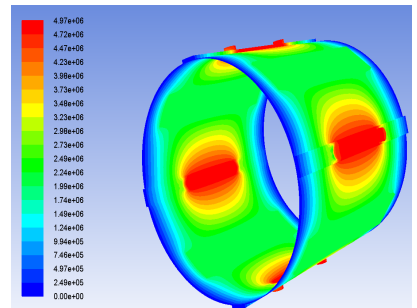

(a) Pressure distribution graph

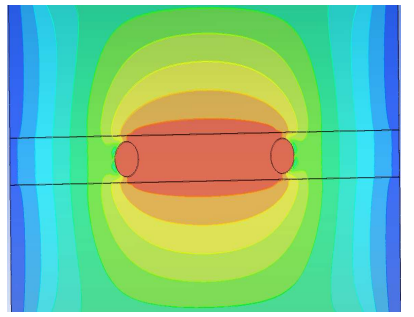

(b) Gradient graph
FIGURE III. PRESSURE DISTRIBUTION AND GRADIENT GRAPHS OF THE OIL FILM BEARING.

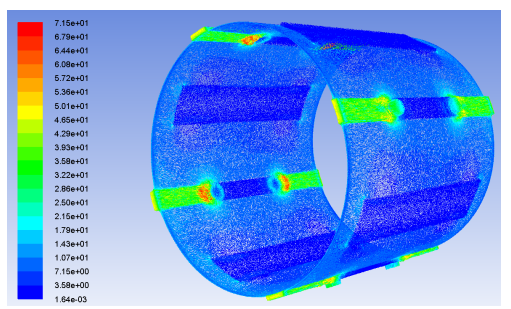

FIGURE IV. OIL FLOW DISTRIBUTION GRAPH OF THE OIL FILM BEARING.

It can be seen that from Figure.3: high pressure regions focus on mainly between two oil entrance holes on each oil guide groove; in the circumferential direction, taking each oil guide groove as the center, oil film pressure decreases towards two sides, until confluence in each static pressure oil cavity; in the axial direction, oil film pressure decreases gradually towards two edges of the bearing, and the lowest oil film pressure occurs on the edges of the bearing. It can be seen that from Figure.4: oil flow distribution of the oil film bearing is relatively homogeneous; the highest flow speed appears in the regions from oil entrance hole on each oil guide groove to the edge of the bearing, and the slowest flow speed regions are located in four static pressure oil cavities; on the other hand, it can be seen obviously that a part of lubrication oil flows directly out from each oil guide groove, that is to say, this part of lubrication oil is not involved in inner oil circulation of the bearing, and this will increase the power of oil supply system and affect seriously oil film performance of the bearing. 
According to above analyses, diffusibility of oil film pressure and oil flow property of the bearing are not good, and the most serious problem is that a part of lubrication oil flows directly out from each oil guide groove. The key cause is the bearing body shown in Figure. 1 has some structure defects, specifically speaking, the structure of four oil guide grooves and the locations of oil entrance holes need to be optimized. Therefore, structure of the bearing body shown in Figure.1 must be improved, so that its flow field performances can be enhanced obviously.

\section{NUMERICAL ANALYSIS OF FLOW FIELD OF THE IMPROVED OIL FILM BEARING}

Structure of the improved bearing body is shown in Figure.5. In comparison with the structure shown in Figure.1, dimensions of four oil guide grooves are shorten from $100 \mathrm{~mm}$ to $80 \mathrm{~mm}$, and the distance dimensions from two ends of each oil guide groove to the edge of the bearing are both $10 \mathrm{~mm}$, that is to say, each oil guide groove is not cut through the edge of the bearing; two oil entrance holes on each rectangle rib are replaced by a middle oil entrance hole. According to the above same method, flow field performances of the improved oil film bearing shown in Figure.5 are analyzed.

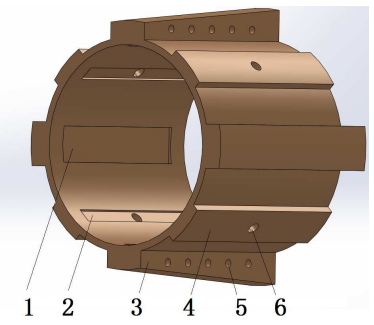

1. Static pressure oil cavity; 2 . Oil guide groove; 3 . Tapered rib; 4 Rectangle rib; 5. Oil guide hole; 6 . Oil entrance hole

FIGURE V. STRUCTURE OF THE IMPROVED BEARING BODY.
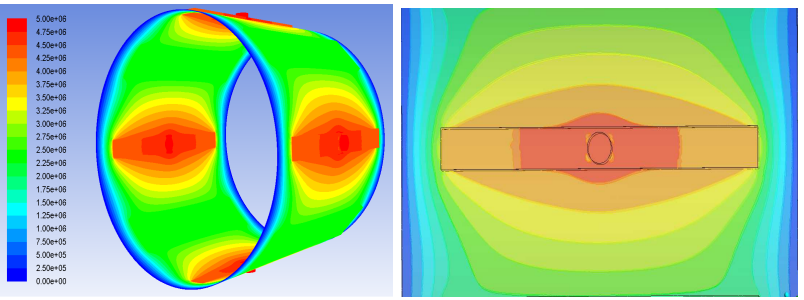

(a) Pressure distribution graph (b) Gradient graph

FIGURE VI. PRESSURE DISTRIBUTION AND GRADIENT GRAPHS OF THE IMPROVED BEARING.

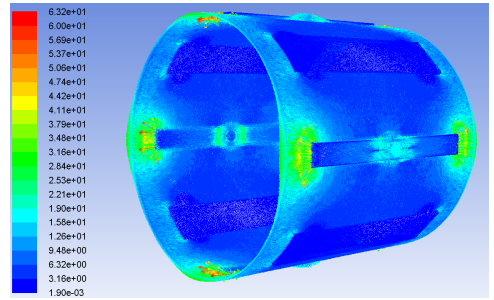

FIGURE VII. OIL FLOW DISTRIBUTION GRAPH OF THE IMPROVED BEARING.
Based on finite element calculation, pressure distribution graph, gradient graph and oil flow distribution graph of the improved bearing at the spindle speed of $1500 \mathrm{r} / \mathrm{min}$ are acquired, as are shown in Figure. 6 and Figure. 7 respectively.

It can be seen that from Figure.6 and Figure.7: diffusibility of oil film pressure of the improved bearing is enhanced obviously whether in the circumferential direction or in the axial direction. As for oil flow property, because each oil guide groove is not cut through the edge of the bearing, oil is forced to participate in inner oil circulation of the bearing, thus, the phenomenon of oil outflow is restrained effectively; in addition, because two oil entrance holes on each rectangle rib are replaced by a middle oil entrance hole, oil flow property is further improved, and this embodies mainly as follows: oil entering into the bearing from oil entrance holes is all involved in inner oil circulation of the bearing, furthermore, in comparison with before improvement, the whole oil flow is accelerated. In summary, diffusibility of oil film pressure and oil flow property are both improved, thus, on the one hand, premise and guarantee are provided for forming oil film which is needed for the bearing at high-speed running condition and maintaining pure liquid friction; on the other hand, oil circulation is accelerated, as is benefit for heat dissipation of the bearing; more important, oil renewal in four static pressure oil cavities is also accelerated, thus, pocketed oil phenomenon in four static pressure oil cavities is improved effectively.

\section{CONCLUSIONS}

Structure defects of a kind of oil film bearing in highspeed roll grinder are found by means of numerical analysis of flow field performances, therefore, the structure of the bearing is improved: dimensions of four oil guide grooves are shorten, each oil guide groove is not cut through the edge of the bearing, and two oil entrance holes are replaced by a middle oil entrance hole. For the improved bearing, diffusibility of oil film pressure is enhanced obviously, the phenomenon of oil outflow is restrained effectively, and oil entering into the bearing is all involved in inner oil circulation of the bearing; furthermore, the whole oil flow is accelerated. In a word, the improved bearing has good diffusibility of oil film pressure and oil flow property, thus, heat dissipation property and pocketed oil phenomenon of the bearing can be improved greatly, and powerful theoretical support is also provided for its practical application.

\section{ACKNOWLEDGEMENTS}

This project is supported by National Natural Science Foundation of China (Grant No. 51165002, 51465008), the Tribology Science Fund of State Key Laboratory of Tribology (Grant No. SKLTKF12A11), and Special Fund of Training Objects on Excellent Young Talents of Science and Technology in Guizhou Province (Grant No. (2013)17).

\section{REFERENCES}

[1] C.R. Zhu, Ultra-high speed grinding and its key technology. Grinding Machine Tool and Grinding, 4, pp. 51-52, 2000. (In Chinese)

[2] H.H. Zhao, B.F. Feng \& G.B. Gao, et al, Application of ultra-high speed grinding technologies in the field of the mechanical machining. 
Journal of Northeastern University (Natural Science), 24(6), pp. 564568, 2003. (In Chinese)

[3] X.J. Gao \& H.H. Zhao, Development and situation of high speed and ultrahigh speed grinding process. Journal of Liaoning University of Petroleum \& Chemical Technology, 24(4), pp. 43-46, 2004. (In Chinese)

[4] Rowe, W.B., Morgan, M.N. \& Black, S.C.E., Validation of thermal properties in grinding. CIRP Annals Manufacturing Technology, 47(1), pp. 275-279, 1998

[5] Hwang, T.W., Evans, C.J. \& Malkin, S., High speed grinding of silicon nitride with electroplated diamond wheels, part 2: Wheel topography and grinding mechanisms. Journal of Manufacturing Science and Engineering, 122(1), pp. 42-50, 2000.

[6] L. Guo \& B. Li, Optimal design of hydro-hybrid bearing in super high speed grinder spindle. Journal of Hunan University of Arts and Science (Natural Science Edition), 18(3), pp. 53-55, 2006. (In Chinese)

[7] F.F. Wang, W. Chen \& Y.F. Zhang, Simulation on the flow fields of a novel water-lubricated static and dynamic hybrid bearing for highspeed spindle. Lubrication Engineering, 35 (12), pp. 28-31, 2010. (In Chinese)

[8] T. Ma, H.L. Dai \& S.R. Liu, Numerical simulation study on liquid hybrid bearing based on FLUENT. Journal of Donghua University (Natural Science), 36(3), pp. 279-282, 2010. (In Chinese) 